\title{
Clinical study of transcanal closure of tympanic membrane perforations using a collagen sponge
}

\author{
A TAMAE ${ }^{1,2}, \mathrm{~S} \mathrm{KOMUNE}^{2}$ \\ ${ }^{1}$ Department of Otolaryngology, Hamanomachi Hospital, Fukuoka, and ${ }^{2}$ Department of Otorhinolaryngology, \\ Graduate School of Medical Sciences, Kyushu University, Fukuoka, Japan
}

\begin{abstract}
Materials and methods: We used an artificial dermis (Terdermis ${ }^{\circledR}$ ), which is an atero-collagen sponge covered with a sheet of silicon.

Patients: Nineteen ears of 17 patients with perforation of the tympanic membrane under various conditions, including large and wet perforations, underwent operation using this collagen sponge.

Results: The success rate of closure after the initial surgery was $8 / 19$. The overall success rate of closure after initial and re-operation was 14/19. The success rate of closure was $12 / 14$ for small-sized perforations, $1 / 4$ for middle-sized perforations and 1/1 for a large-sized perforation. Middle- and large-sized perforations required multiple surgeries. The success rate of closure was $11 / 11$ for dry perforations, $3 / 4$ for perforations with light otorrhoea and $0 / 4$ for perforations with extensive otorrhoea.

Conclusion: This surgery is a low-cost and minimally invasive surgery and has a high closure rate. This surgery is effective on small-sized, dry perforations although it can also close middle- and large-sized dry perforations.
\end{abstract}

Key words: Tympanic Membrane Perforation; Otitis Media; Myringoplasty; Collagen Sponge

\section{Introduction}

Tympanic membrane perforations are closed by various methods, such as myringoplasty with post-auricular incision, and transcanal closure of the membrane using a variety of materials. In 1989, Yuasa developed a simple underlay myringoplasty procedure using fibrin glue, ${ }^{1}$ since then, it has been widely performed in Japan to close small dry perforations and has a high success rate without serious complications. ${ }^{2,3}$ However, Yuasa's method does require fibrin glue, which is a relatively expensive material. Recently, transcanal closure of the tympanic membrane using a collagen sponge (Terdermis ${ }^{\circledR}$ ), the cost of which is relatively low, has been reported in Japan ${ }^{4-8}$ and small dry perforations underwent operation in the Japanese reports. The aim of the present study is to introduce transcanal closure of the tympanic membrane using this collagen sponge to European and American doctors and to investigate the effectiveness of this surgery and its indications. The present study shows a success rate of closing perforations under various conditions including large and wet perforations.

\section{Materials and methods}

We used artificial dermis (Terdermis ${ }^{\mathbb{R}}$ ), which is an atero-collagen sponge with a sheet of silicon.
Terdermis $^{\circledR}$ is divided into an upper layer and lower layer. The upper layer is a sheet of silicon and the lower layer is collagen, which is made from the dermis of a young cow. It is developed in a sponge form by combining fibrillar collagen (F-collagen) with gelatin. The sponge is physically and metabolically stabilised by introducing dehydrothermal cross-links. ${ }^{9}$

Patients lay on an operating table and the operation is performed under an operating microscope. After administration of local anaesthesia, the margins of the tympanic membrane perforations are trimmed through the extra-auditory canal to create a fresh wound. The artificial dermis is cut to a larger size than the trimmed perforation and the sheet of silicon is peeled back from the collagen layer at the outer edge of the artificial dermis. The artificial dermis is then placed over the perforation, with the sheet of silicon on top of the perforation rim and the collagen layer underneath it (Figure 1). Usually this surgery takes less than 15 minutes. A few weeks later, the sheet of silicon is removed, and the surgery is repeated in cases where the perforation is not filled with collagen or granulation. In all cases, the perforation filled with collagen or granulation was epithelialised in a few weeks, depending on the size of the perforation (Figures 2-1 and 2-2). 


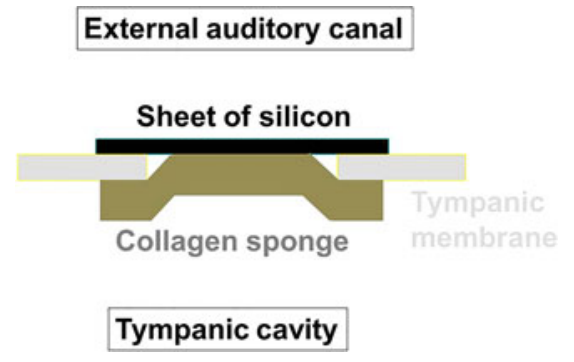

FIG. 1

The artificial dermis was placed on the perforation, with the sheet of silicon on top and the collagen layer adjacent to the tissue.

\section{Patients}

Between August 2008 and May 2010, 19 ears of 17 patients with perforation of the tympanic membrane underwent an operation in which a collagen sponge was used as the grafting material for reconstruction of the tympanic membrane. The indication for attempted closure by collagen sponge was any perforation seen by the transcanal approach. In this study, we tried operation on both wet perforations and large perforations.
The cause of tympanic perforation was chronic otitis media in 11 , insertion of a tympanic ventilation tube in 3 and failure of tympanoplasty or myringoplasty in 5. Eleven ears were dry, four ears had light otorrhoea and four ears had more extensive otorrhoea. Fourteen ears had small-sized perforations (a size one-quarter of the tympanum or less), four ears had middle-sized perforations (one-half) and one ear had a large-sized perforation (three-quarters or more) (Table I).

\section{Results}

The success rate of closure after the initial surgery was $8 / 19$. Two ears needed two surgeries, one needed three surgeries and two needed more than four surgeries for closure. This surgery failed to close perforations in five ears. The overall success rate of closure after the initial and repeat operation was 14/19 (Figure 3). Size of perforation and extent of otorrhoea had strong relationships with the success rate of closure either initially or after repeat operation.

Regarding the size of perforation, the success rate of closure was $12 / 14$ for small-sized perforations, $1 / 4$ for (a)

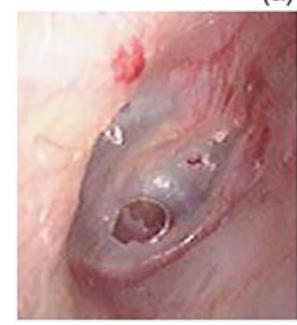

(b)

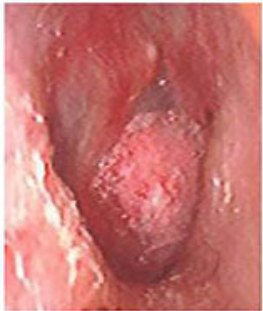

(c)

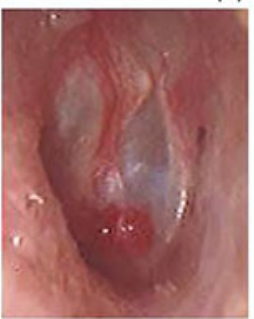

(d)

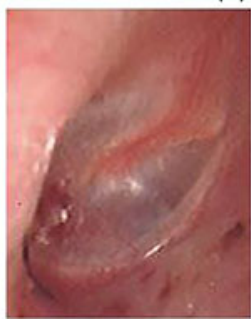

FIG. 2-1

Small-sized perforation (a) Initial surgery was performed. (b) Day 14. Sheet of silicon was removed. (c) Day 28. Tympanic membrane was epithelialised.

(a)

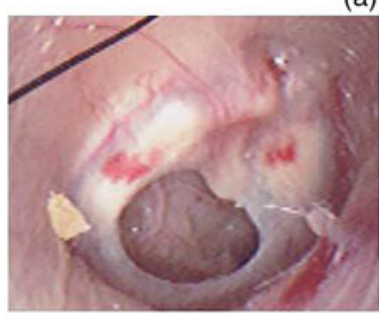

(d) a)

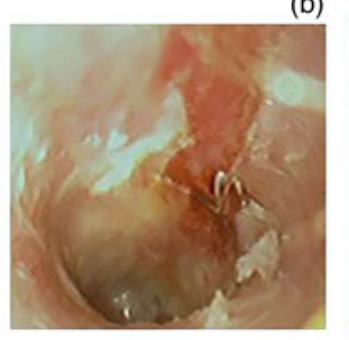

(e)

(b)

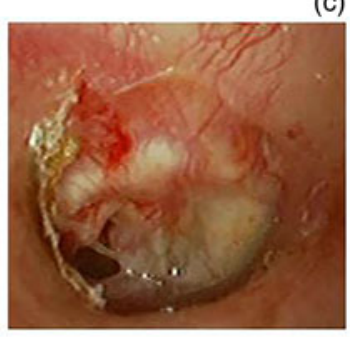

(f)
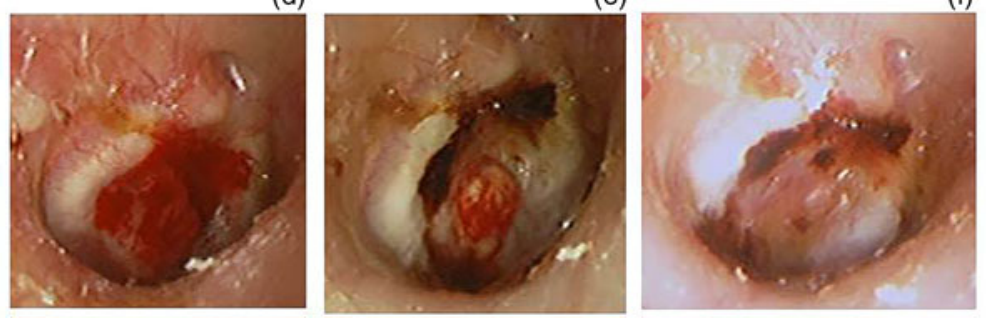

FIG. 2-2

(a) Large-sized perforation. (b) Initial surgery was performed. (c) Day 7. Sheet of silicon was removed and the perforation was not filled with collagen. Second surgery was performed. (d) Day 21. Sheet of silicon was removed and the perforation was filled with collagen. (e) Day 28.

Tympanic membrane was not epithelialised. (f) Day 42. Tympanic membrane was epithelialised. 


\begin{tabular}{|c|c|c|c|c|c|}
\hline & & $\begin{array}{c}\text { TABLE I } \\
\text { CONDITIONS OF }\end{array}$ & & & \\
\hline Age & Cause of perforation & Size of perforation & Otorrhoea & Number of surgeries & Result \\
\hline 68 & Chronic otitis media & Small & None & 1 & Closed \\
\hline 12 & Insertion of a tympanic ventilation tube & Small & None & 1 & Closed \\
\hline 12 & Insertion of a tympanic ventilation tube & Small & None & 1 & Closed \\
\hline 52 & Chronic otitis media & Small & None & 1 & Closed \\
\hline 84 & Chronic otitis media & Small & None & 1 & Closed \\
\hline 43 & Fail of tympanoplasty & Small & None & 1 & Closed \\
\hline 61 & Chronic otitis media & Small & None & 1 & Closed \\
\hline 74 & Insertion of a tympanic ventilation tube & Small & None & 2 & Closed \\
\hline 77 & Chronic otitis media & Small & None & 2 & Closed \\
\hline 52 & Chronic otitis media & Large & None & 2 & Closed \\
\hline 88 & Chronic otitis media & Middle & None & 3 & Closed \\
\hline 57 & Chronic otitis media & Small & Light & 1 & Closed \\
\hline 49 & Fail of myringoplasty & Small & Light & 5 & Failed to close \\
\hline 49 & Fail of tympanoplasty & Small & Light & More than 5 & Closed \\
\hline 55 & Fail of tympanoplasty & Small & Light & More than 5 & Closed \\
\hline 58 & Chronic otitis media & Middle & Extensive & 1 & Failed to close \\
\hline 69 & Chronic otitis media & Middle & Extensive & 3 & Failed to close \\
\hline 86 & Chronic otitis media & Middle & Extensive & 3 & Failed to close \\
\hline 77 & Fail of tympanoplasty & Small & Extensive & 5 & Failed to close \\
\hline
\end{tabular}

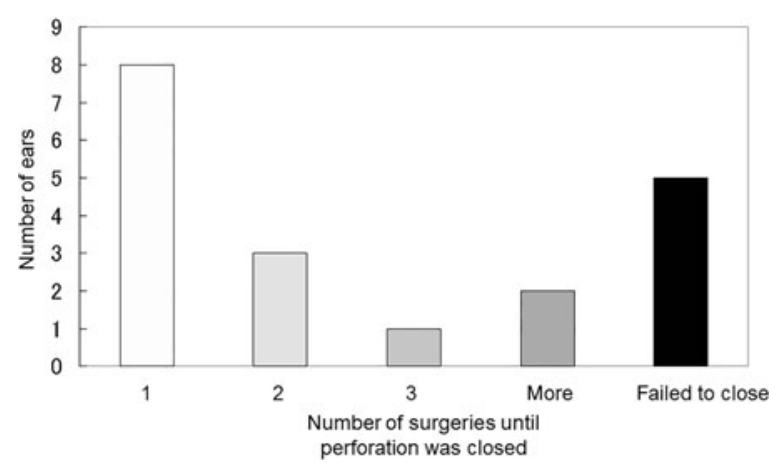

FIG. 3

Number of surgeries before perforation was closed. The success rate of closure after the initial surgery was $8 / 19$. The overall success rate of closure after initial and repeat operation was $14 / 19$.

middle-sized perforations and $1 / 1$ for the large-sized perforation. The middle- and large-sized perforations required multiple surgeries (Figure 4).

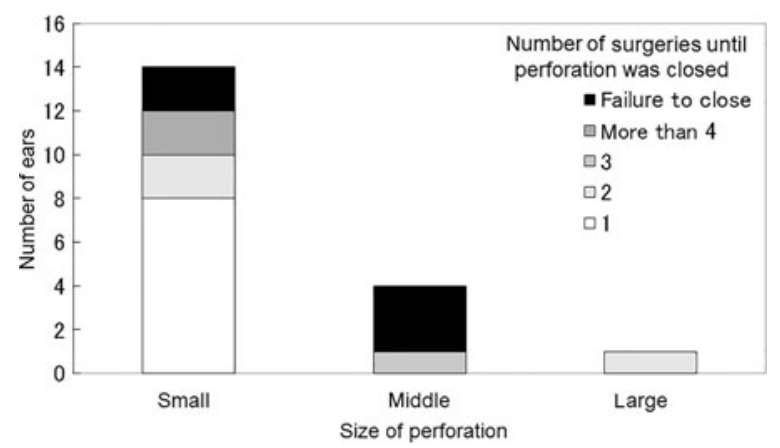

FIG 4

Number of surgeries before perforation was closed by size of perforation. The success rate of closure was $12 / 14$ for small-sized perforations, $1 / 4$ for middle-sized perforations and $1 / 1$ for large-sized perforation. Multiple surgeries were needed for middle- and largesized perforations.
Regarding the cause of perforation, the success rate of closure was $8 / 11$ for chronic otitis media, $3 / 3$ for insertion of a tympanic ventilation tube and $3 / 5$ for failure of tympanoplasty or myringoplasty (Figure 5).

Regarding the extent of otorrhoea, the success rate of closure was $11 / 11$ for dry perforations and $3 / 4$ for perforations with light otorrhoea. Some perforations required multiple surgeries. The success rate of closure was $0 / 4$ for perforations with more extensive otorrhoea. One ear with light otorrhoea and three ears with more extensive otorrhoea for which this surgery failed were later closed by simple underlay myringoplasty with fibrin glue (Figure 6).

\section{Discussion}

In the present study, regardless of the size and cause of perforation, all surgeries for perforation with extensive otorrhoea failed. Collagen sponges are vulnerable to infection because they are artefacts.

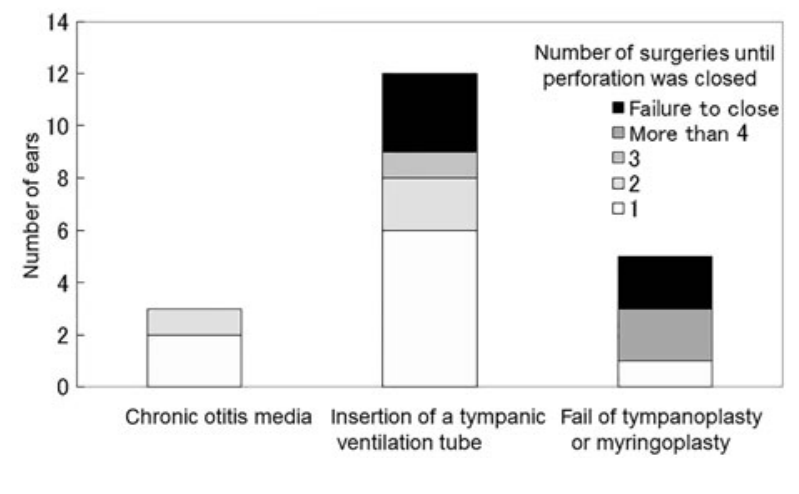

FIG. 5

Number of surgeries before perforation was closed by cause of perforation. The success rate of closure was $8 / 11$ for chronic otitis media, $3 / 3$ for insertion of a tympanic ventilation tube and $3 / 5$ for failure of tympanoplasty or myringoplasty. 


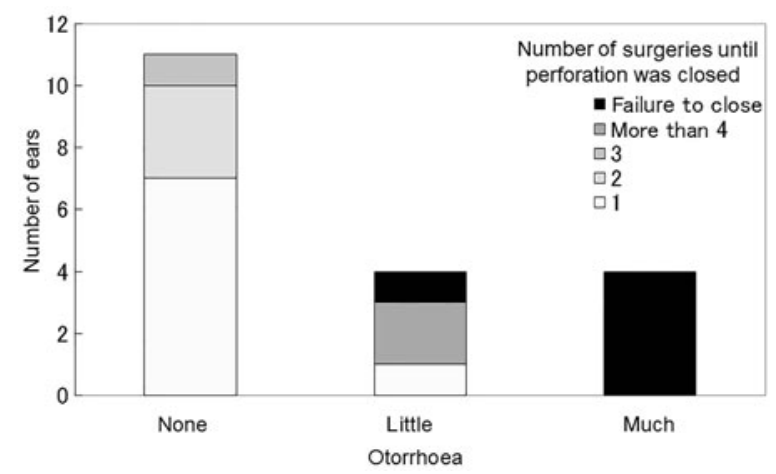

FIG. 6

Number of surgeries before perforation was closed by degree of otorrhoea. The success rate of closure was $11 / 11$ for dry perforations, $3 / 4$ for perforations with light otorrhoea and $0 / 4$ for perforations with extensive otorrhoea.

Several wet-ear perforations which could not be closed by this surgery were closed by simple underlay myringoplasty with fibrin glue. Hence, this present collagen-sponge surgery is not more suitable for dealing with infection than simple underlay myringoplasty. On the other hand, the success rate of closure after initial surgery for dry perforations was 63.6 per cent (7/11), and all dry perforations (11/11) were closed after re-operation. Excluding the perforations with extensive otorrhoea, the success rate of closure after the initial surgery was 53.3 per cent $(8 / 15)$, and the overall success rate of closure after initial and repeat operation was 93.3 per cent $(14 / 15)$. Ears with extensive otorrhoea had a significantly higher failure rate compared with ears without extensive otorrhoea ( $p=$ 0.0013, Fisher's exact test) (Table II). Reports in Japan using this type of collagen substrate have found success rates of closure after the initial surgery and after repeat operation of 42.1-71.4 and 66.7-90.9 per cent, and have found the greatest success with dry, small or middle-sized perforations. $^{4-8}$ It seems fairly certain that this type of surgery is more effective on dry perforations and if wet, for perforations without active infection.

TABLE II
THE SUCCESS RATE OF CLOSURE BY DEGREE OF
OTORRHOEA

Hakuba reported closing tympanic membrane perforations with a collagen sponge and basic fibroblast growth factor, and pointed out that this surgery is minimally invasive and has a high success rate. ${ }^{10}$ But that study used basic fibroblast growth factor. Our results suggest that fibroblast growth factor is not necessary to close dry perforations, because all dry perforations were closed after initial and repeat operations in the present study without this growth factor.

Among our patients, the overall success rate after initial and repeat operation did not depend on the size of the perforation. However, the number of surgeries may depend on the size of the perforation. Of 14 small-sized perforations, 8 were closed by the initial surgery, whereas none of the 5 middle- and largesized perforations was closed on the first try. At the initial surgery, middle- and large-sized perforations have a significantly high failure rate compared with small-sized perforations ( $p=0.0013$, Fisher's exact test) (Table III). Both middle- and large-sized perforations that were closed after re-operation required multiple surgeries. The collagen sponge shrinks after surgery, and technically it is difficult to place the collagen sponge with a sheet of silicon in a large perforation without there being a gap because it cannot bend. Therefore, with larger perforations there is often a postoperative gap between the collagen sponge and the perforation, requiring multiple surgeries. But these disadvantages are not a problem for small-sized perforations. Although middle- and large-sized perforations can be closed by this surgery, it takes time and effort.

Recently, transcanal closure of a tympanic membrane using a collagen sponge (Terdermis ${ }^{\circledR}$ ) has been reported in Japan. ${ }^{4-8}$ Some reports used a collagen sponge with a sheet of silicon ${ }^{4,5,8}$ and some reports used a collagen sponge without a sheet of silicon., There are two reasons why we used a collagen sponge with a sheet of silicon. First, it is easier to place the collagen sponge with a sheet of silicon when the sheet of silicon is peeled back from the edges of the collagen layer. Without the silicon sheet,

\begin{tabular}{|c|c|c|}
\hline \multicolumn{3}{|c|}{$\begin{array}{l}\text { THE SUCCESS RATE OF CLOSURE BY SIZE OF } \\
\text { PERFORATION }\end{array}$} \\
\hline & $\begin{array}{c}\text { Success rate of } \\
\text { closure after } \\
\text { initial surgery }\end{array}$ & $\begin{array}{l}\text { Success rate of } \\
\text { closure after initial } \\
\text { and re-operation }\end{array}$ \\
\hline $\begin{array}{l}\text { Small-sized } \\
\text { perforation }\end{array}$ & $57.1 \%(8 / 14)^{*}$ & $85.7 \%(12 / 14) \dagger$ \\
\hline $\begin{array}{l}\text { Middle- and large- } \\
\text { sized perforation }\end{array}$ & $0 \%(0 / 5)^{*}$ & $40 \%(2 / 5) \dagger$ \\
\hline All ears & $42.1 \%(8 / 19)$ & $73.7 \%(14 / 19)$ \\
\hline
\end{tabular}

${ }^{*} p=0.029$ Fisher's exact test.

$\dagger p=0.84$ Fisher's exact test.

At the initial surgery, middle- and large-sized perforations had a significantly higher failure rate compared with small-sized perforations ( $p=0.0013$, Fisher's exact test). 
it would be difficult to cut the collagen patch to an adequate size because the collagen sponge shrinks after surgery, and might easily fall through the perforation if not cut large enough. On the other hand, a collagen sponge with a sheet of silicon does not need to be cut to exact size when using this method of peeling back the silicon and sliding the collagen sponge underneath the rim of the perforation. Even if the silicon is peeled too much, the patch can still be placed over the perforation without a gap. Second, the collagen sponge with a sheet of silicon is stably fixed because the sheet of silicon overlays the rim of the perforation while the collagen underlays it. The collagen does not fall into the tympanic cavity because the sheet of silicon is larger than the trimmed perforation. Third, the sheet of silicon protects the collagen sponge until epithelialisation. The disadvantage is that it must be removed after epithelialisation, but this does not take much time. Several articles have reported surgery to close the tympanic membrane using AlloDerm ${ }^{\circledR} .{ }^{11-13}$ But in these articles, it was used as the grafting material for reconstruction of the tympanic membrane in myringoplasty or tympanoplasty. AlloDerm is difficult to place in the perforation without fibrin glue. A collagen sponge with a sheet of silicon is better than Alloderm as an artificial dermis to be placed in a perforation.

Tympanic membrane perforations are closed by various methods. In Japan, Yuasa developed simple underlay myringoplasty with fibrin glue in $1989^{1}$ and this method has been widely performed to close small dry perforations. Sakagami identified several reasons why simple underlay myringoplasty with fibrin glue has been widely performed in Japan. ${ }^{2}$ Transcanal closure of a tympanic membrane using a collagen sponge has some of the same advantages described by Sakagami. Although closure with a paper patch or tape is generally performed in traumatic perforations and after ventilation tube removal, $4,14,15$ transcanal closure of a tympanic membrane using a collagen sponge can be applied to persistent tympanic perforation. It has been reported that simple underlay myringoplasty causes no serious complications and was safely introduced to bilateral same-day surgery ${ }^{2,16}$ Transcanal closure of a tympanic membrane using a collagen sponge and simple underlay myringoplasty have the same procedure with regard to tympanic membrane; therefore, transcanal closure of a tympanic membrane using a collagen sponge is as safe and simple as underlay myringoplasty. Since neither procedure damages the tympanic membrane, the surgeon can easily try another surgery such as myringoplasty and tympanoplasty when the initial surgeries fail to close the perforation.

Further, transcanal closure of a tympanic membrane perforation using a collagen sponge has some advantages compared with simple underlay myringoplasty. First, it takes less time. This surgery does not need a retroauricular incision, because it does not need connective tissue such as subcutaneous tissue or temporalis fascia. Second, its cost is relatively low, because the collagen sponge is a cheap material while fibrin glue is relatively expensive. Third, it is minimally invasive. This surgery does not require a retroauricular incision. Fourth, it does not carry the risk of viral infection through fibrin glue. Use of blood products has been questioned from a safety standpoint.

- Transcanal closure of a tympanic membrane perforation using a collagen sponge (Terdermis ${ }^{\circledR}$ ) has been reported in Japanese but not in English. The present study introduces transcanal closure of the tympanic membrane using this collagen sponge to doctors from other countries

- In the Japanese reports, small dry perforations underwent operation. The present study shows a success rate of closing perforations under various conditions including large and wet perforations and investigates the effectiveness of this surgery and its indications

On the other hand, it has some disadvantages. A collagen sponge is vulnerable to infection because it is an artefact, and closure of large-sized perforations takes time and effort.

Therefore it is necessary to be able to perform both simple underlay myringoplasty with fibrin glue and transcanal closure of a tympanic membrane using collagen sponge, depending on the case. Small-sized dry perforations are indicated for transcanal closure of a tympanic membrane using a collagen sponge, although large-sized perforations and wet perforations without active infection can be closed by this surgery as well.

\section{Conclusion}

Transcanal closure of a tympanic membrane using a collagen sponge is a low-cost and minimally invasive surgery and showed a high success rate. This surgery is most effective on small-sized dry perforations although large-sized perforations and wet perforations without active infection can be closed by this surgery as well.

References

1 Yuasa R, Saijo S, Tomioka Y, Kusakari C, Kakehata S, Katori Y et al. Office closure of eardrum perforation with fibrin glue [in Japanese]. Otolaryngol Head Neck Surg (Tokyo) 1989;61: 1117-22

2 Sakagami M, Yuasa R, Yuasa Y. Simple underlay myringoplasty. J Laryngol Otol 2007;121:840-4

3 Yuasa Y, Yuasa R. Postoperative results of simple underlay myringoplasty in better hearing ears. Acta Otolaryngol 2008;128: 139-43

4 Sakoda T, Shibano A, Saitoh Y, Dake Y, Sogo M, Fujimura S et al. An office technique for myringoplasty without the use of fibrin glue [in Japanese]. Nihon Jibiinkoka Gakai Kaiho 2000;103:836-9

5 Kouchi A, Kusumi A, Ura M. Myringoplasty using an artificial dermis [in Japanese]. Otologia Fukuoka 2000;46:285-9. 
6 Shimogori H, Miura M, Sugahara K, Kamata T, Fukui K, Yamachita $\mathrm{H}$. Treatment for post-operative tympanic perforation using Terudamis $\left.^{(}\right)$[in Japanese]. Otology Japan 2000;10: 198-200

7 Tsuji T, Omori K, Yamamoto E, Tasaka Y, Shimohara S. A new 'Collagen Sponge' artificial dermis for repair of tympanic membrane defacts and external auditory canal skin defects at the outpatient clinic [in Japanese]. Practica Oto-Rhino-Laryngologica 2001;94:781-90

8 Fukami S, Hirabayashi H, Baba K, Haruma S. Clinical study of tympanic perforation closure technique using collagen sponge (Terudermis $^{\circledR}$ ) [in Japanese]. Otology Japan 2007; 17:638-43

9 Koide M, Osaki K, Oyamada K, Katakura T, Takahashi A, Yoshizato K. A new type of biomaterial for artificial skin: dehydrothermally cross-linked composites of fibrillar and denatured collagens. J Biomed Mater Res 1993;27:79-87

10 Hakuba N, Taniguchi M, Yoshitaka S, Sugimoto A, Shinomori Y, Gyo K. A new method for closing tympanic membrane perforations using basic fibrast growth factor. Laryngoscope 2003; 113: $1352-5$

11 Fayad JN, Braino T, Parisier SC. Preliminary results with the use of AlloDerm in chronic ottitis media. Laryngoscope 2003;113: 1228-30

12 Fishman AJ, Marrinan MS, Huang TC, Kanowitz SJ. Total tympanic membrane resonstruction: AlloDerm versus temporalis fascia. Otolaryngol Head Neck Surg 2005;132:906-15
13 Vos JD, Latev MD, Labadie RF, Cohen SM, Werkehaven JA, Haynes DS. Use of AlloDerm in type I tympanoplasty: comparison with native tissue grafts. Laryngoscope 2005;115: 1599-602

14 Saito H, Kazama Y, Yazawa Y. Simple maneuver for closing traumatic eardrum perforation by micropore strip tape patching. Am J Otolaryngol 1990;11:427-30

15 Ringenberg JC. Closure of tympanic membane perforation by the use of fat. Laryngoscope 1978;88:982-93

16 Sakagami M, Mishiro Y, Tsuzuki K, Seo T, Sone M. Bilateral same day surgery for bilateral perforated chronic otitis media. Auris Nasus Larynx 2000;27:35-8

Address for correspondence:

Dr Akihiro Tamae,

Department of Otolaryngology,

Hamanomachi Hospital,

Nagahama 3-3-1, Chuou-ku,

Fukuoka 810-8539, Japan

E-mail: tamae-a@hamanomachi.jp

Competing interests: None declared 